\title{
Potencial erosivo e características das chuvas de São Gabriel, RS, de 1963 a 1993
}

\author{
Flávio L. F. Eltz ${ }^{1}$, Elemar A. Cassol ${ }^{2}$, Pedro B. Pascotini ${ }^{3} \&$ Ricardo S. S. Amorim ${ }^{4}$
}

\begin{abstract}
RESUMO
Conhecer a erosividade da chuva é fundamental para ações de controle da erosão em cada região, devido à sua alta variabilidade temporal e espacial. O objetivo deste trabalho foi determinar a erosividade, os padrões hidrológicos, o coeficiente de chuvas e o período de retorno das chuvas de São Gabriel, RS, com base nos dados de registro dos pluviogramas diários para o período de 1963 a 1993. Para cada chuva considerada erosiva foram anotados o tempo e a altura de cada segmento com mesma intensidade, sendo calculados a erosividade pelo parâmetro $\mathrm{El}_{30}$, seus totais mensais e anuais e os padrões hidrológicos das chuvas, $\mathrm{O}$ coeficiente de chuvas, o período de retorno e a probabilidade de ocorrência. O período de outubro a maio concentra $75 \%$ da erosividade anual, com pico maior em fevereiro (712 MJ mm ha- $\left.\mathrm{h}^{-1}\right)$. Os padrões avançado, intermediário e atrasado têm 52, 21 e $27 \%$ do número de chuvas erosivas perfazendo 55, 21 e $24 \%$ do volume médio anual e 58,21 e $21 \%$ da erosividade média anual, respectivamente. A erosividade

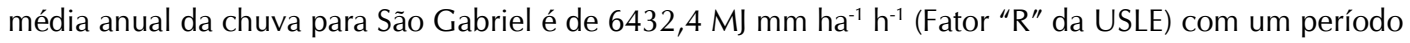
de retorno de 2,7 anos e probabilidade de ocorrência de $37,5 \%$.
\end{abstract}

Palavras-chave: padrões hidrológicos de chuva, índice $\mathrm{El}_{30}$, erosividade, fator $\mathrm{R}$

\section{Erosive potential and rainfall characteristics of São Gabriel, RS, Brazil, from 1963 to 1993}

\begin{abstract}
The knowledge of rainfall erosivity is fundamental for actions of erosion control in each region, due to its high variability in time and space. The objective of this study was to determine the rainfall erosivity, the hydrological patterns, the rainfall coefficient and the return period of erosive rainfalls of São Gabriel (RS, Brazil), based on the period of 1963 to 1993. For each erosive rainfall, the hour and the height of each rainfall with the same intensity were digitalized, and the $\mathrm{El}_{30}$ index, the monthly and annual totals, the hydrological pattern, the rainfall coefficient, the return period and its probability occurrence were calculated. The period of October to May concentrates $75 \%$ of the annual erosivity, with larger peak in February $(712 \mathrm{MJ} \mathrm{mm}$ $\mathrm{ha}^{-1} \mathrm{~h}^{-1}$ ). The advanced, intermediary and delayed patterns have 52,21 , and $27 \%$ of the number of erosive rainfalls, corresponding to 55,21 and $24 \%$ of the annual volume of erosive rainfalls and 58,21 and $21 \%$ of the mean annual erosivity, respectively. For São Gabriel, the mean annual rainfall erosivity index is 6432.4

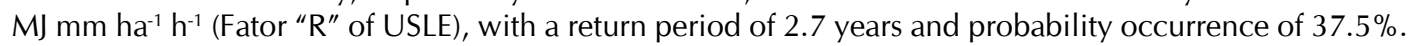

Key words: hydrological rainfall patterns, $\mathrm{El}_{30}$ index, erosivity, $\mathrm{R}$ factor

Professor aposentado do Departamento de Solos da UFSM, Av. Roraima, no. 1000, Cidade Universitária, Bairro Camobi, Santa Maria, RS, CEP 97105-900. E-mail: flavioeltz@gmail.com

2 Departamento de Solos/UFRGS, Av. Bento Gonçalves, 7712, Bairro Agronomia, Porto Alegre, RS, CEP 91540-000. E-mail: elemar.cassol@ufrgs.br

${ }^{3}$ Mestrando do PPG em Engenharia Ambiental, UFSM. Av. Roraima no. 1000, Cidade Universitária, Bairro Camobi, CEP 97105-900. Santa Maria, RS. Departamento de Engenharia Sanitária e Ambiental. E-mail: pedropascotini@gmail.com

${ }^{4}$ Departamento de Solos e Engenharia Rural/UFMT. Av. Fernando Correa da Costa, s/n, Campus UFMT, Cuiabá, MT. CEP 78060-900 E-mail: rsamorim@ufmt.br 


\section{INTRODUÇÃO}

A erosão é a principal forma de degradação dos solos agrícolas sendo a chuva um dos fatores que influenciam o processo de erosão. Conhecer o potencial erosivo das chuvas de uma região é importante para predizer a erosão, que pode ser estimada com modelos matemáticos, a exemplo da Equação Universal de Perdas de Solo (Wischmeier \& Smith, 1978). A erosividade da chuva, conhecida como fator $\mathrm{R}$ da equação universal de perda de solo, representa o potencial erosivo médio das chuvas de uma região tomados, como base, períodos de 20 a 30 anos de dados pluviográficos (Wischmeier, 1959). Para cada chuva a erosividade é determinada pelo parâmetro $\mathrm{EI}_{30}$, que representa o produto da energia cinética total da chuva $(\mathrm{E}$, em $\mathrm{MJ} \mathrm{ha}^{-1}$ ) pela intensidade máxima em $30 \mathrm{~min}\left(\mathrm{I}_{30}\right.$, em mm $\mathrm{h}^{-1}$ ), com base na precipitação máxima para o período de 30 min. $\mathrm{O}$ parâmetro $\mathrm{EI}_{30}$ foi considerado adequado para estimar a erosividade das chuvas no Rio Grande do Sul (Morais et al., 1988) baseado em estudo de correlações com as perdas de solo por erosão.

A chuva causa erosão e danos em infraestrutura urbana e rural, com grande frequência. $\mathrm{O}$ dimensionamento de obras hidráulicas e conservacionistas, como terraços, pode ser feito quando é conhecido o período de retorno das chuvas e de sua erosividade.

O pico de maior intensidade da chuva tem influência direta na erosão do solo. Partindo desta observação, Horner \& Jens (1942) caracterizaram as chuvas em padrões hidrológicos chamados avançado, intermediário e atrasado, respectivamente, quando o pico de maior intensidade da chuva ocorre nos primeiro, segundo e terceiro terços do período de duração total da chuva. No Rio Grande do Sul os padrões hidrológicos foram caracterizados por Mehl et al. (2001) em Santa Maria, por Peñalva-Bazzano et al. (2007) em Quaraí, por Cassol et al. (2007) em Ijuí, por Cassol et al. (2008) em São Borja, por Mazurana et al. (2009) em Santa Rosa e por Peñalva-Bazzano et al. (2010) em Rio Grande, sendo o padrão avançado o de maior frequência em todos os locais estudados. Entretanto, esses resultados não garantem que outros locais tenham o mesmo comportamento; daí, sente-se a necessidade de que seja estudado o maior número de locais com dados disponíveis.

O objetivo deste trabalho foi determinar a erosividade, o período de retorno e os padrões hidrológicos das chuvas para a região de São Gabriel, no Estado do Rio Grande do Sul.

\section{Material e Métodos}

O município de São Gabriel, RS, se situa entre as coordenadas de latitude $30^{\circ} 27^{\prime} \mathrm{S}$ e longitude $54^{\circ} 19^{\prime} \mathrm{W}$, numa altitude de $109 \mathrm{~m}$ na região fisiográfica da Campanha Gaúcha. O clima é do tipo Cfa (clima temperado úmido com verão quente), conforme a classificação de Köeppen (Moreno, 1961). A temperatura média mensal é de $19,5{ }^{\circ} \mathrm{C}$, sendo $24,9{ }^{\circ} \mathrm{C}$ a média das temperaturas máximas e de $14,2{ }^{\circ} \mathrm{C}$ a média das temperaturas mínimas. A precipitação média anual normal de 30 anos, avaliada no período de 1976 a 2005, é de 1.423,9 mm, com chuvas bem distribuídas ao longo do ano, com mínimo de $80,1 \mathrm{~mm}$ no mês de agosto e o máximo de $146,6 \mathrm{~mm}$ no mês de abril (CEMETRS, 2011).
Os pluviogramas diários foram obtidos pela estação agrometeorológica da FEPAGRO (Fundação Estadual de Pesquisa Agropecuária) com amplitude de $10 \mathrm{~mm}$, unidades de $0,1 \mathrm{~mm}$ e tempo de registro de $24 \mathrm{~h}$ e unidades de $10 \mathrm{~min}$, com leitura realizada com precisão de $5 \mathrm{~min}$. $\mathrm{O}$ índice $\mathrm{EI}_{30}$ foi determinado para cada chuva individual erosiva a qual é assim considerada quando ocorre uma precipitação igual ou superior a $10 \mathrm{~mm}$, ou menor, mas que tenha no mínimo uma precipitação de $6,0 \mathrm{~mm}$ em tempo igual ou inferior a $15 \mathrm{~min}$. Cada chuva é separada de outra quando ocorre um período mínimo de 6 h sem chuva ou com precipitação menor que 1,0 $\mathrm{mm}$, conforme critérios sugeridos por Wischmeier \& Smith (1978) e modificados por Carvalho et al. (1989).

Para o cálculo do $\mathrm{EI}_{30}$ o registro da chuva em cada pluviograma diário foi separado em segmentos de mesma inclinação, que representam períodos de mesma intensidade. Em planilha foram registrados as horas e os minutos do dia quando houve variação de intensidade e a chuva acumulada até aquele momento. Depois de digitados os dados foram processados pelo programa CHUVEROS, elaborado pelo Prof. Elemar Antonino Cassol, conforme metodologia de Wischmeier (1959) obtendo-se a erosividade de cada chuva e, pela soma dos valores individuais, os valores mensais e anuais. A média dos valores anuais corresponde ao fator R da Equação Universal de Perdas de Solo (Wischmeier, 1959) expresso em MJ mm $\mathrm{ha}^{-1} \mathrm{~h}^{-1}$, segundo o Sistema Internacional de Unidades (Foster et al., 1981).

Foram determinados os padrões hidrológicos das chuvas analisadas (Horner \& Jens, 1942) classificados em padrões hidrológicos avançado, intermediário e atrasado, respectivamente, quando a localização do pico de maior intensidade ocorre no início (primeiro terço), meio (segundo terço) e no fim (terceiro terço) do período de duração da chuva. Com base neste critério calculou-se a porcentagem do total das chuvas que representa cada padrão hidrológico, em número, volume e erosividade.

Com os dados da série pluviográfica de São Gabriel, RS (1963-1993) foram ajustadas as equações matemáticas que representam as relações linear e potencial entre a erosividade das chuvas $\left(\mathrm{EI}_{30}\right)$ e o coeficiente de chuvas conforme proposto por Lombardi Neto (1977) dadas pelas seguintes expressões:

$$
\begin{gathered}
\mathrm{EI}_{30}=\mathrm{a}+\mathrm{b} \times \mathrm{Rc} \\
\mathrm{EI}_{30}=\mathrm{a} \times \mathrm{Rc}^{\mathrm{b}}
\end{gathered}
$$

onde:

$\mathrm{EI}_{30}$ - índice de erosividade das chuvas, $\mathrm{MJ} \mathrm{mm} \mathrm{ha}^{-1} \mathrm{~h}^{-1}$

$\mathrm{a}$ e $\mathrm{b}$ - coeficientes de ajuste

Rc - coeficiente de chuva, em mm, dado pela relação: Rc $=\mathrm{Pm}^{2} \mathrm{~Pa}^{-1}$, em que Pm é a precipitação pluvial média mensal, em mm, e Pa é a precipitação pluvial média anual, em mm.

O período de retorno e a probabilidade de ocorrência da erosividade anual foram determinados, conforme Schwab et al. (1981), por meio das seguintes expressões:

$$
\mathrm{T}=\frac{(\mathrm{N}+1)}{\mathrm{m}}
$$




$$
\operatorname{Pr}=\frac{100}{\mathrm{~T}}
$$

onde:

T - período de retorno, em anos, no qual o índice de erosividade é igualado ou superado

$\mathrm{N} \quad$ - número de anos de registro de dados

m - número de ordem do índice de erosividade da série considerada quando a erosividade é colocada em ordem decrescente de magnitude

Pr - probabilidade de ocorrência do índice de erosividade, em porcentagem.

\section{Resultados E Discussão}

No período de 1963 a 1993 foram analisadas 1.049 chuvas erosivas, tendo ocorrido outras 1.412 chuvas classificadas como não erosivas, o que mostra uma média anual de 34 chuvas erosivas e 46 não erosivas. Em relação ao número total ocorreram $42,6 \%$ de chuvas erosivas e $57,4 \%$ de chuvas não erosivas; já em relação ao volume, as chuvas erosivas perfizeram $88,4 \%$, com apenas $11,6 \%$ do volume total de chuvas não erosivas no período de 31 anos (Figura 1) significando que grande parte da precipitação tem condições de causar

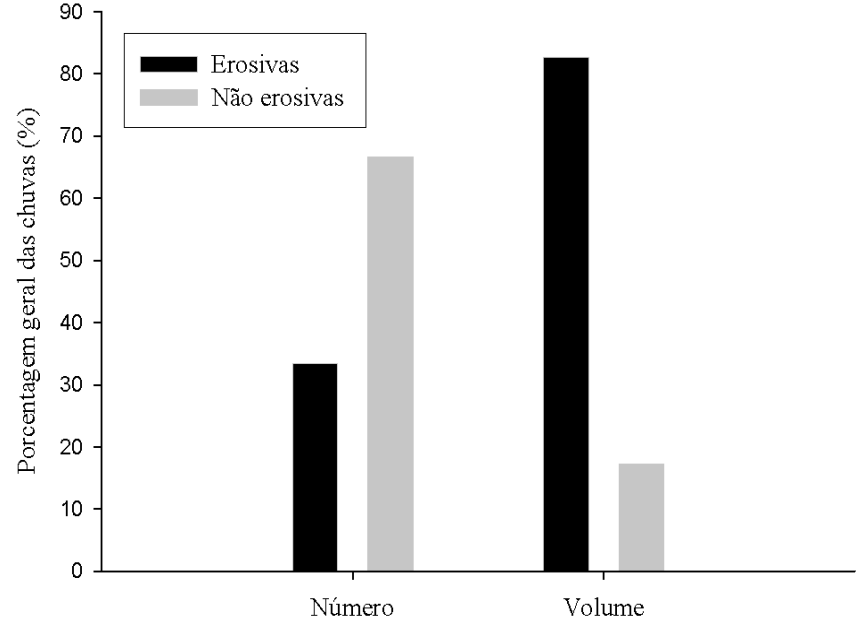

Figura 1. Número e volume de chuvas erosivas e não erosivas ocorridas em São Gabriel, RS, no período de 1963 a 1993

erosão do solo, o que sinaliza maior necessidade de cuidados conservacionistas por parte dos agricultores.

A precipitação média anual em São Gabriel, RS, no período de 1963 a 1993, foi de 1.182,8 mm (Tabela 1), com o valor mínimo de 671,8 mm ocorrido em 1971 e máximo de 1.764,4 mm em 1966. Devido à alta variabilidade das precipitações, a

Tabela 1. Valores de precipitação pluvial (mm) em São Gabriel, RS, no período de 1963 a 1993

\begin{tabular}{|c|c|c|c|c|c|c|c|c|c|c|c|c|c|}
\hline Anos & Jan & $\overline{F e v}$ & Mar & $\overline{A b r}$ & Mai & Jun & Jul & Ago & Set & Out & Nov & $\overline{D e z}$ & Total \\
\hline 1963 & 113,3 & 31,2 & 246,5 & 0,0 & 125,3 & 50,3 & 92,2 & 35,4 & 164,9 & 394,2 & 255,2 & 53,0 & $1.561,5$ \\
\hline 1964 & 60,4 & 87,6 & 39,5 & $107,8^{*}$ & 0,0 & 25,8 & 33,3 & 118,1 & 137,0 & 19,0 & $87,3^{*}$ & 81,2 & 797,0 \\
\hline 1965 & 44,7 & 10,0 & 32,6 & 112,5 & 45,0 & 47,8 & 12,4 & 162,7 & 194,6 & 181,2 & 30,1 & 75,2 & 948,8 \\
\hline 1966 & 75,3 & 176,1 & 309,5 & 62,2 & $108,9^{\star}$ & 163,0 & 267,5 & 69,6 & 147,1 & $106,5^{\star}$ & 72,8 & 205,9 & $1.764,4$ \\
\hline 1967 & 69,7 & 51,9 & 29,2 & 74,1 & 134,8 & 70,3 & 112,9 & 130,2 & 70,2 & 99,0 & 77,4 & 23,2 & 942,9 \\
\hline 1968 & 103,5 & 0,0 & 213,6 & 89,6 & 48,2 & 29,2 & 66,8 & 12,4 & 120,9 & 127,2 & 91,1 & 162,5 & $1.065,0$ \\
\hline 1969 & 160,9 & 153,9 & 59,5 & 47,8 & 144,5 & 107,9 & 107,9 & 73,4 & 42,1 & 73,0 & 175,0 & 73,2 & $1.219,1$ \\
\hline 1970 & 44,1 & 170,1 & 100,4 & 50,6 & 153,7 & 111,4 & 101,5 & 39,3 & 22,2 & 144,9 & 8,6 & 177,2 & $1.124,0$ \\
\hline 1971 & 78,1 & 126,1 & 0,0 & 12,1 & 0,0 & 151,2 & 41,7 & 102,2 & 38,8 & 71,8 & 10,0 & 39,8 & 671,8 \\
\hline 1972 & 205,2 & 78,2 & 92,5 & 67,1 & 168,8 & 269,7 & 137,3 & 177,5 & 179,9 & 103,7 & 57,8 & 14,2 & $1.551,9$ \\
\hline 1973 & 141,2 & 323,1 & 25,9 & 166,2 & 64,3 & 65,3 & 184,0 & 81,0 & 65,7 & 97,6 & 14,5 & 148,7 & $1.377,5$ \\
\hline 1974 & 100,1 & 126,0 & 19,1 & 18,6 & 79,1 & 81,4 & 112,5 & 147,9 & 128,9 & $106,5^{*}$ & $87,3^{*}$ & $78,2^{*}$ & $1.085,6$ \\
\hline 1975 & $92,4^{*}$ & $97,0^{*}$ & $88,6^{*}$ & $107,8^{*}$ & $108,9^{*}$ & $96,3^{*}$ & 62,3 & 172,6 & 188,9 & 42,3 & 130,8 & 54,7 & $1.242,5$ \\
\hline 1976 & 152,8 & 40,3 & 231,9 & 56,0 & 51,5 & 40,6 & 106,1 & 84,3 & 69,4 & 147,5 & 130,8 & 86,0 & $1.197,2$ \\
\hline 1977 & 141,6 & 85,4 & 74,0 & 206,4 & 77,0 & 82,8 & 227,3 & 113,4 & 105,0 & 126,9 & 87,0 & 24,8 & $1.351,6$ \\
\hline 1978 & 48,7 & 12,4 & 92,6 & 28,9 & 93,7 & 92,2 & 197,1 & 25,4 & 73,8 & 118,2 & 153,1 & 69,8 & $1.005,9$ \\
\hline 1979 & 0,0 & 22,0 & 49,3 & 122,1 & 93,3 & 16,6 & 140,2 & 183,3 & 296,8 & 147,0 & 76,0 & 23,3 & $1.169,9$ \\
\hline 1980 & 20,0 & 59,5 & 211,5 & 88,1 & 85,0 & 147,5 & 55,0 & 0,0 & 27,9 & 278,3 & 77,4 & 58,4 & $1.108,6$ \\
\hline 1981 & 80,6 & 106,8 & 21,6 & 48,1 & 65,5 & 63,7 & 76,7 & 20,2 & 120,6 & 16,6 & 33,5 & 96,7 & 750,6 \\
\hline 1982 & 52,7 & 225,0 & 0,0 & 0,0 & 163,1 & 132,0 & 248,6 & 93,7 & 221,5 & 222,8 & 211,1 & 27,1 & $1.597,6$ \\
\hline 1983 & 126,4 & 229,7 & 75,2 & 238,7 & 118,2 & 38,4 & 183,6 & 13,6 & 109,0 & 20,8 & 0,0 & 11,0 & $1.164,6$ \\
\hline 1984 & 161,1 & 62,6 & 19,0 & 160,5 & 369,5 & 184,5 & 68,5 & 53,3 & 133,0 & 60,1 & 113,0 & 40,0 & $1.425,2$ \\
\hline 1985 & 0,0 & 32,9 & 160,2 & 175,2 & 146,8 & 130,0 & 136,8 & 134,9 & 181,4 & 44,2 & 0,0 & 19,7 & $1.162,1$ \\
\hline 1986 & 107,7 & 152,5 & 53,0 & 130,1 & 240,7 & 80,3 & 57,6 & 43,8 & 124,1 & 163,3 & 285,4 & 78,2 & $1.516,7$ \\
\hline 1987 & 107,5 & 61,6 & $88,6^{*}$ & 252,3 & 121,3 & 31,6 & 340,2 & 177,6 & 124,1 & 72,9 & 68,2 & 93,6 & $1.539,5$ \\
\hline 1988 & 148,6 & $97,0^{*}$ & $88,6^{*}$ & $107,8^{*}$ & $108,9^{*}$ & 135,1 & $122,2^{*}$ & $80,9^{*}$ & $116,7^{*}$ & 57,0 & 130,9 & 0,0 & $1.193,7$ \\
\hline 1989 & 109,1 & $97,0^{*}$ & 48,1 & 79,2 & 0,0 & 36,4 & 46,7 & $80,9^{*}$ & 76,1 & 12,4 & 11,6 & 78,2 & 675,7 \\
\hline 1990 & $92,4^{\star}$ & $97,0^{*}$ & 16,0 & $107,8^{*}$ & $108,9^{*}$ & $96,3^{*}$ & $122,2^{*}$ & $80,9^{\star}$ & $116,7^{*}$ & $106,5^{*}$ & $87,3^{*}$ & $78,2^{\star}$ & $1.003,6$ \\
\hline 1991 & 39,1 & $97,0^{*}$ & $88,6^{*}$ & 291,9 & 28,3 & 103,1 & 77,9 & 0,0 & 51,0 & 74,6 & 33,3 & 213,7 & $1.098,5$ \\
\hline 1992 & 55,0 & 65,4 & 127,3 & 280,4 & 192,2 & 179,4 & 144,8 & 0,0 & 145,4 & 65,2 & 11,6 & 85,5 & $1.352,2$ \\
\hline 1993 & 132,6 & 30,4 & 44,2 & 51,6 & 130,5 & 123,9 & 104,4 & 0,0 & 23,8 & 0,0 & 98,9 & 152,6 & 892,9 \\
\hline MÁX & 205,2 & 323,1 & 309,5 & 291,9 & 369,5 & 269,7 & 340,2 & 183,3 & 296,8 & 394,2 & 285,4 & 213,7 & $1.764,4$ \\
\hline MíN & 0,0 & 0,0 & 0,0 & 0,0 & 0,0 & 16,6 & 12,4 & 0,0 & 22,2 & 0,0 & 0,0 & 0,0 & 671,8 \\
\hline Média & 92,4 & 97,0 & 88,6 & 107,8 & 108,9 & 96.3 & 122,2 & 80,9 & 116,7 & 106,5 & 87.3 & 78,2 & $1.182,8$ \\
\hline
\end{tabular}

MÁX. - Valor máximo da série. MíN. - Valor mínimo da série. * Significa que o valor não foi observado devido à inexistência do dado de chuva tendo-se utilizado o valor médio do referido mês da série levantada 
média obtida no período de 1963 a 1993 é diferente da obtida no período de 1976 a 2005, pelo CEMETRS (2011).

A distribuição mensal da precipitação tem, em média, maiores valores em julho e setembro, com 122,2 e 116,7 mm, respectivamente, e menor valor com 78,2 $\mathrm{mm}$ em dezembro, apresentando a ocorrência de extremos, como a ausência de chuva em vários meses e valor máximo de $394,2 \mathrm{~mm}$ em outubro de 1963. A distribuição da precipitação mensal em São Gabriel, RS, mostrada na Tabela 1, indica menores frequências de precipitações extremas e maior frequência de precipitações baixas ao longo do ano caracterizando uma boa distribuição de chuvas ao longo do ano.

A erosividade mensal de São Gabriel, RS (Tabela 2) variou de zero em vários meses em que não ocorreram chuvas erosivas até 3.048,8 $\mathrm{MJ} \mathrm{mm} \mathrm{ha}^{-1} \mathrm{~h}^{-1}$, como o ocorrido em abril de 1991; este último representa $38,9 \%$ da erosividade do ano. Neste mês de abril de 1991 apenas duas chuvas representaram $80 \%$ desta erosividade, o que as caracteriza como altamente erosivas. Edwards \& Owens (1991) observaram, em Coshocton, Ohio, USA, que cinco eventos de chuva foram responsáveis por $66 \%$ da erosão ocorrida no período de 28 anos, com mais de 4.000 eventos de chuva. O estudo desses eventos é importante para cada município de maneira que possam ser conhecidos seu potencial erosivo, distribuição e frequência e tomadas medidas práticas de conservação do solo que possam prevenir seus danos.

A erosividade média mensal foi máxima em fevereiro, com valor de 711,5 $\mathrm{MJ} \mathrm{mm} \mathrm{ha}^{-1} \mathrm{~h}^{-1} \mathrm{e}$ mínima em agosto, com valor de 252,6 MJ mm ha ${ }^{-1} \mathrm{~h}^{-1}$ (Tabela 2). A distribuição mensal mostra um período em junho, julho, agosto e setembro, com menores valores de potencial erosivo e outro período em outubro a maio, com valores maiores, que concentram $75 \%$ do poder erosivo anual; neste último período maiores cuidados devem ser tomados para evitar a erosão do solo, como ter as áreas agrícolas devidamente cobertas por culturas e/ou resíduos de culturas e evitar o preparo convencional do solo. Locais com potencial erosivo baixo no período de inverno também foram encontrados no Rio Grande do Sul, por Cogo et al. (2006) para Santa Maria, por Peñalva-Bazzano et al. (2007) em Quaraí, por Cassol et al. (2008) em São Borja e por Mazurana et al. (2009) em Santa Rosa.

A erosividade anual de São Gabriel, RS, variou de 2.808,9 MJ mm ha ${ }^{-1} \mathrm{~h}^{-1}$ em 1971 a 12.096,5 MJ mm ha ${ }^{-1} \mathrm{~h}^{-1}$ em 1987 (Tabela 2). No último ano o potencial erosivo de dois meses (julho e agosto) representou $28,8 \%$ do potencial erosivo deste ano. Foi de 6.432,4 MJ mm ha-1 $\mathrm{h}^{-1}$ o valor médio obtido para os 31 anos da série de dados pluviográficos (Tabela 2) o qual representa o fator "R" da USLE, que pode ser utilizado com

Tabela 2. Valores mensais e anuais do índice de erosividade $\mathrm{EI}_{30}\left(\mathrm{MJ} \mathrm{mm} \mathrm{ha}^{-1} \mathrm{~h}^{-1}\right.$ ) em São Gabriel, RS, no período de 1963-1993

\begin{tabular}{|c|c|c|c|c|c|c|c|c|c|c|c|c|c|}
\hline Anos & Jan & Fev & Mar & Abr & Mai & Jun & Jul & Ago & Set & Out & Nov & Dez & Total \\
\hline 1963 & 909,3 & 235,1 & $2.384,6$ & 0,0 & 396,1 & 99,6 & 404,0 & 43,1 & 490,7 & $2.546,6$ & $1.930,0$ & 127,5 & $9.566,6$ \\
\hline 1964 & 378,0 & 418,7 & 108,8 & $701,3^{\star}$ & 0,0 & 23,6 & 88,2 & 277,7 & 430,0 & 14,7 & $539,9^{\star}$ & 296,5 & $3.277,4$ \\
\hline 1965 & 208,8 & 30,1 & 125,5 & & 106,5 & 76,4 & 19,1 & 371,5 & 625,7 & $1.326,3$ & & 364,4 & $3.793,7$ \\
\hline 1966 & 513,7 & $1.982,7$ & $2.094,1$ & 321,9 & $567,7^{*}$ & $1.260,1$ & $1.428,4$ & 32,9 & 720,4 & $540,5^{*}$ & 138,7 & $1.951,4$ & $11.702,6$ \\
\hline 1967 & 300,7 & 180,3 & 119,8 & 618,4 & 386,6 & 92,5 & 221,0 & 414,0 & 130,3 & 344,6 & 347,8 & 28,0 & $3.184,0$ \\
\hline 1968 & 826,0 & 0,0 & $1.712,4$ & 155,5 & 174,5 & 46,0 & 116,4 & 6,8 & 230,5 & 450 & 404,9 & $2.157,1$ & $6.280,9$ \\
\hline 1969 & $1.258,4$ & $1.123,0$ & 198,5 & 78,5 & 493,9 & 278,0 & 110,2 & 228,7 & 32,0 & 324 , & $1.384,0$ & 575,3 & $6.084,8$ \\
\hline 1970 & 236,5 & $1.113,2$ & 273,3 & 383,6 & 945,1 & 236,5 & 401,3 & 53, & 13,3 & 800,0 & 32,7 & $1.717,4$ & $6.206,2$ \\
\hline 1971 & & 764,4 & 0,0 & 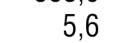 & 0,0 & 807 & 53,2 & 256,7 & 167 & & 48 & 180,9 & \\
\hline 1972 & $1.145,8$ & $1.126,4$ & 367,7 & 182,3 & $2.064,3$ & $1.996,7$ & 312,6 & 716,9 & $1.410,7$ & 323,3 & 161,9 & 48,2 & $9.854,8$ \\
\hline 1973 & & $2.739,4$ & 68,7 & 570,0 & & & 407,9 & 2 & & & & 990,7 & $6.336,0$ \\
\hline 1974 & 8 & 898,9 & 63,7 & 37,1 & 290,7 & 35 & 384,1 & 4 & & $5 *$ & & $95,3^{*}$ & 77,8 \\
\hline 1975 & $594,2^{*}$ & $711,5^{\star}$ & $598,3^{\star}$ & $701,3^{*}$ & $567,7^{\star}$ & $406,0^{\star}$ & 253,2 & 200,7 & 456,0 & & & 372,4 & $5.685,4$ \\
\hline 1976 & $1.517,5$ & 242,3 & $2.907,3$ & 387,2 & 93,7 & 75,8 & 275,8 & 1 & 280,5 & 849 & 51 & 487,7 & $7.776,1$ \\
\hline 1977 & 0,3 & 483,0 & 354,5 & 883,2 & 343,7 & 459,0 & $1.116,0$ & 276 & 464,0 & 525 & & 37,4 & $6.150,0$ \\
\hline 1978 & 160,0 & 64,6 & 500,8 & 25,2 & 264,1 & 230,3 & 486,0 & 127 & 242,4 & 323 & & 178,8 & $3.133,9$ \\
\hline 1979 & 0,0 & & 124,5 & 409,2 & 628,4 & 25 & 349,3 & 838,9 & $2.770,9$ & & & & $6.146,3$ \\
\hline 1980 & 77,5 & 220,2 & $1.275,5$ & 262,1 & 131,8 & 324,3 & 83,2 & 0,0 & 42,7 & 983, & 42 & 181,6 & $4.010,2$ \\
\hline 1981 & 481,3 & & 209,0 & 102,0 & & & & 96 & & 75 & & & $2.827,2$ \\
\hline 1982 & 217,8 & $1.279,4$ & 0,0 & 0,0 & 559,9 & 521,3 & $1.075,5$ & 161 & 95 & 329,0 & $.487,2$ & 186,4 & $9.870,8$ \\
\hline 1983 & 801,4 & $1.792,9$ & 191,9 & 49,7 & 262,3 & 73,3 & 464,1 & 27 & 168,8 & 36,5 & 0,0 & 44,9 & $5.912,8$ \\
\hline 1984 & $1.104,7$ & & & & $2.849,0$ & & 213,0 & 102 & & 112,4 & 289,0 & 152,8 & $7.870,6$ \\
\hline 1985 & 0,0 & 192,1 & $1.557,2$ & $1.188,0$ & 564,6 & $1.082,7$ & 588,3 & 312,9 & 720,8 & 170,6 & 0,0 & 87,1 & $6.464,4$ \\
\hline 1986 & 151 & $1.357,1$ & & & $1.548,3$ & 174,0 & & & & & 7,6 & 5,3 & \\
\hline 1987 & $1.085,4$ & 411,8 & $598,3^{*}$ & 2.0 & 644,8 & 22,4 & $2.105,9$ & 1.3 & 78 & 132,3 & 483,2 & $2.475,1$ & $12.096,5$ \\
\hline 1988 & $1.005,8$ & $711,5^{\star}$ & $598,3^{*}$ & $701,3^{*}$ & $567,7^{*}$ & 879,6 & $416,1^{*}$ & & $508,9^{*}$ & 252,9 & 894,4 & 0,0 & $6.789,2$ \\
\hline 1989 & 698,8 & $711,5^{\star}$ & 113,4 & 532,2 & 0,0 & 54,9 & 86,5 & $252,6^{\star}$ & 272,5 & 9,7 & 17 & 595,3 & $3.344,9$ \\
\hline 1990 & $594,2^{*}$ & $711,6^{*}$ & 18,3 & $701,3^{*}$ & $567,7^{*}$ & $406,0^{*}$ & $416,1^{*}$ & $252,6^{*}$ & $508,9^{*}$ & $540,5^{*}$ & $539,9^{*}$ & $595,3^{*}$ & $5.852,4$ \\
\hline 1991 & 2218 & & 5 & $.048,8$ & 56,9 & & 163,2 & 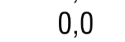 & & 481,4 & & $1.787,7$ & $7.842,7$ \\
\hline 1992 & 251,7 & & 902,7 & 2.0 & 985,3 & & 372,2 & 0 & 807,3 & 171,6 & & 663,1 & $7.530,9$ \\
\hline 1993 & $1.177,5$ & & 127,2 & & 963,1 & & & 0 & & 0,0 & & 98,0 & $4.846,0$ \\
\hline Média & & & 598,3 & 701,3 & 567,7 & 406,0 & 416,1 & 252,6 & 508,9 & 540,5 & 539,9 & 595,3 & $6.432,4$ \\
\hline Máx & $1.517,5$ & 39,4 & 907,3 & $3.048,8$ & 849,0 & $1.996,7$ & 105,9 & $.315,0$ & $.770,9$ & 546,6 & $2.487,2$ & $2.475,1$ & $12.096,5$ \\
\hline Mín & 0,0 & 0,0 & 0,0 & 0,0 & 0,0 & 22,4 & 19,1 & 0,0 & 13,3 & 0,0 & 539,9 & 595,3 & $2.808,8$ \\
\hline
\end{tabular}

Máx.: valor máximo da série. Mín.: Valor mínimo da série. * Significa que o valor não foi determinado devido à inexistência do dado de chuva tendo-se utilizado 0 valor médio do referido mês da série levantada 
segurança para localidades próximas a São Gabriel, RS, com características climáticas semelhantes e que carecem dessas informações.

Valores de erosividade anual maiores que os determinados para São Gabriel, RS, foram obtidos para Santa Maria (7.866 MJ mm ha $\mathrm{m}^{-1}$ ) por Cogo et al. (2006), para Quaraí (9.292 MJ $\mathrm{mm} \mathrm{ha}^{-1} \mathrm{~h}^{-1}$ ) por Peñalva-Bazzano et al. (2007), para Uruguaiana (8.875 $\mathrm{MJ} \mathrm{mm} \mathrm{ha}^{-1} \mathrm{~h}^{-1}$ ) por Hickmann et al. (2008), para São Borja (9.751 MJ mm ha'-1 $\mathrm{h}^{-1}$ ) por Cassol et al. (2008), para Santa Rosa (11.217 MJ mm ha-1 $\mathrm{h}^{-1}$ ) por Mazurana et al. (2009) todos no estado do Rio Grande do Sul.

O padrão avançado teve $52 \%$ do número de chuvas erosivas enquanto os padrões intermediário e atrasado tiveram 21 e $27 \%$, respectivamente (Figura 2). O maior número de ocorrência de chuvas do padrão avançado, que se caracteriza pelo pico de maior intensidade no primeiro terço da chuva do ponto de vista de erosão é, de certa maneira, menos prejudicial, de vez que no início da chuva o solo está mais seco e tem maior capacidade de infiltração de água e, em contrapartida, menor volume de escoamento superficial será produzido.

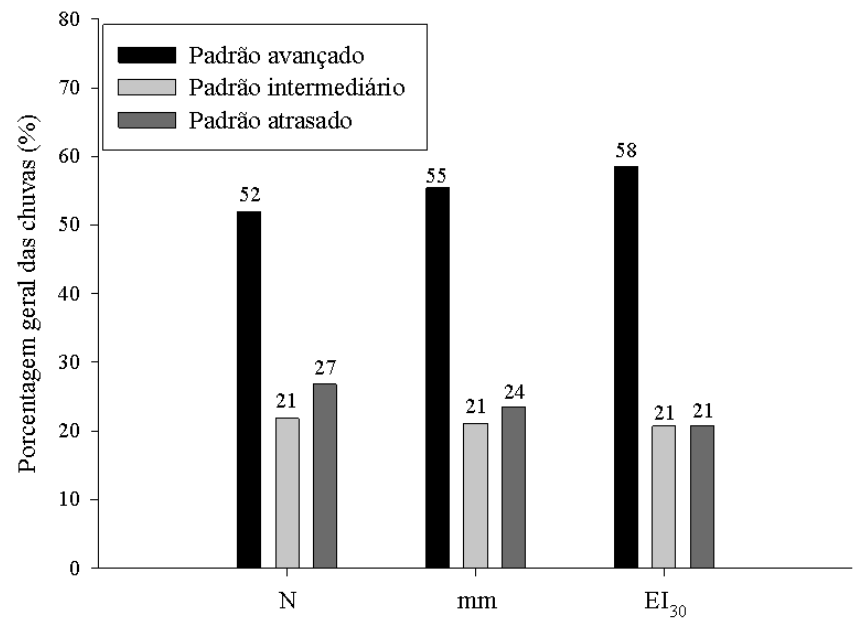

Figura 2. Distribuição por padrões hidrológicos da porcentagem média anual do número $(N)$, da quantidade média anual $(\mathrm{mm})$ e do índice de erosividade médio anual $\left(\mathrm{EI}_{30}\right)$ das chuvas de São Gabriel, RS, no período de 1963 a 1993

Em relação ao volume de chuvas erosivas, a distribuição foi semelhante ao número de chuvas, com 55, 21 e 24\%, respectivamente, para os padrões avançado, intermediário e atrasado. Peñalva-Bazzano et al. (2007) obtiveram 57, 25 e $18 \%$ nos padrões avançado, intermediário e atrasado, respectivamente, no volume de chuvas erosivas em Quaraí, RS, enquanto Cassol et al. (2008) obtiveram, para São Borja, $\mathrm{RS}, 50,26$ e $24 \%$ para esses padrões, revelando uma relativa variabilidade dos padrões de chuva entre as localidades. Porém há, em todas as localidades, predomínio das chuvas de padrão avançado. Para São Gabriel, RS, em relação ao potencial erosivo esta distribuição é mais desigual, ocorrendo 58, 21 e $21 \%$ para os padrões avançado, intermediário e atrasado, respectivamente. As chuvas de padrão avançado podem provocar menor erosão visto que o solo tem mais resistência no início da chuva em virtude do menor selamento superficial, desagregação e transporte do que nas chuvas dos outros padrões (Mehl et al., 2001). Isto foi comprovado por Eltz et al. (2001) que determinaram maior perda de solo por erosão em chuvas do padrão atrasado em relação aos padrões intermediário e avançado, explicado pela alteração da superfície do solo e conteúdo de água no decorrer da chuva.

Em relação ao número de chuvas erosivas mensais, o padrão avançado ocorreu em maior proporção do que os padrões intermediário e atrasado, em todos os meses do ano porém referida proporção é maior nos meses de outubro a abril (Figura 3).

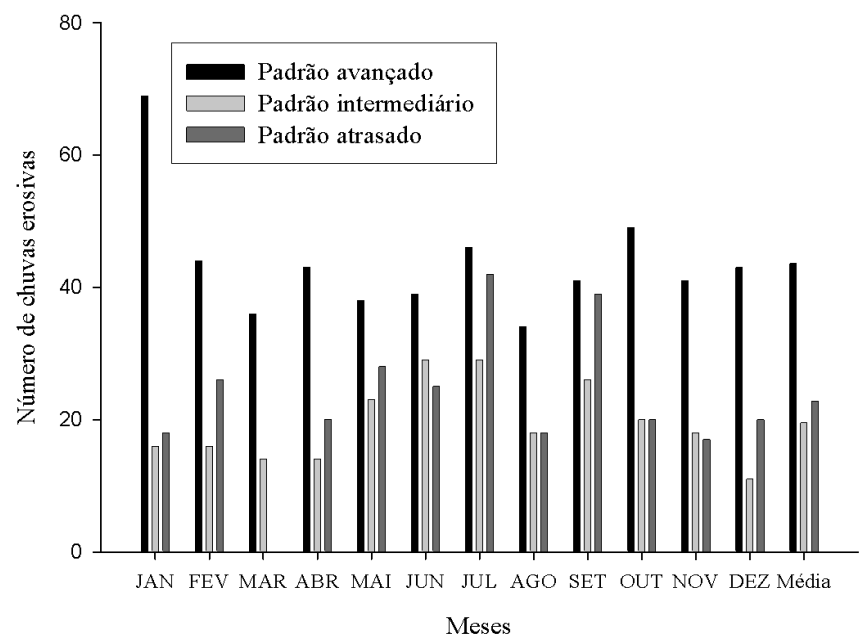

Figura 3. Distribuição do número total mensal por padrões hidrológicos das chuvas erosivas de São Gabriel, RS, no período de 1963 a 1993

A distribuição dos padrões hidrológicos em relação ao volume de chuvas médio mensal foi semelhante à distribuição ocorrida em referência ao número de chuvas, ou seja, o padrão avançado teve maior proporção em todos os meses do ano, com exceção do mês de julho, quando o padrão atrasado teve maior proporção (Figura 4). Do ponto de vista de conservação do solo, isto é benéfico, porque nesta situação a precipitação tem melhores condições de infiltrar no solo.

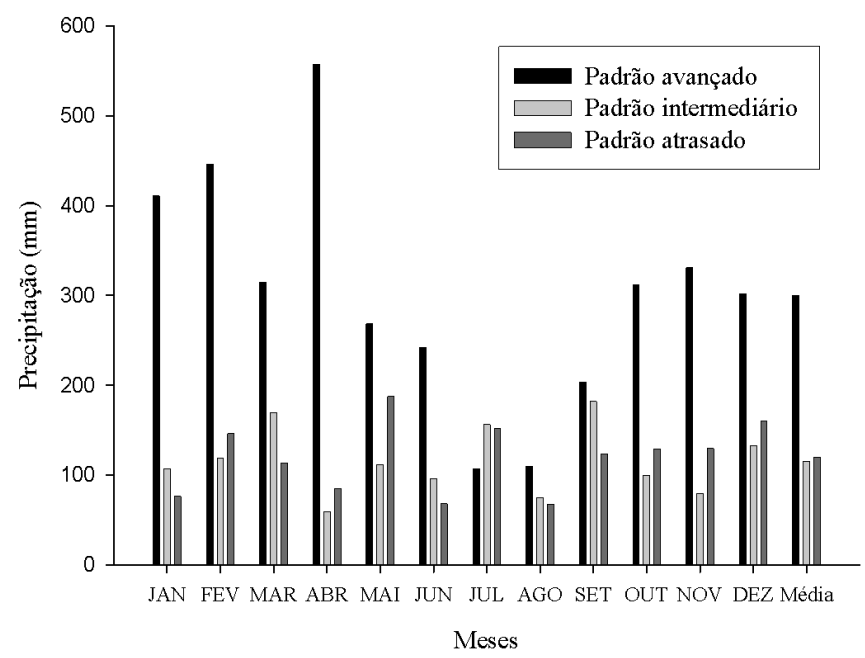

Figura 4. Distribuição da precipitação média mensal por padrões hidrológicos das chuvas erosivas de São Gabriel, RS, no período de 1963 a 1993 
Também em relação à distribuição média mensal da erosividade das chuvas (Figura 5), o padrão avançado ocorreu em maior proporção do que os padrões intermediários e atrasado, sendo esta proporção mais acentuada nos meses de outubro a maio, nos quais o padrão avançado perfaz mais de $50 \%$ da erosividade. Somente no mês de julho o padrão avançado tem proporção menor que os padrões intermediário e atrasado acompanhando a distribuição do volume de chuvas (Figura 5).

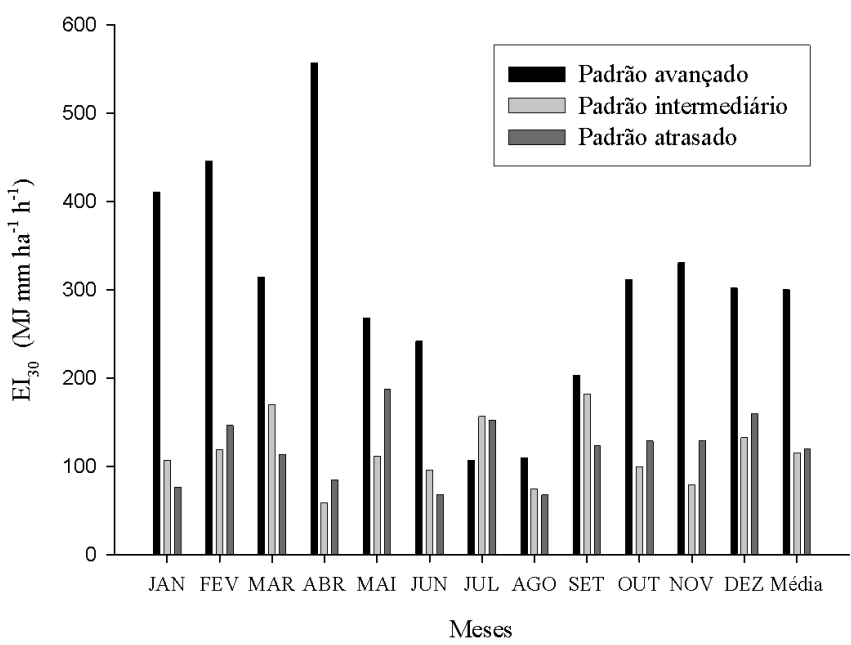

Figura 5. Distribuição da erosividade média mensal por padrões hidrológicos das chuvas erosivas de São Gabriel, RS, no período de 1963 a 1993

As equações matemáticas que representam as relações linear e potencial obtidas entre o coeficiente de chuvas (Rc) e a erosividade das chuvas $\left(\mathrm{EI}_{30}\right)$ foram dadas pelas seguintes expressões:

$$
\begin{array}{cc}
\mathrm{EI}_{30}=518,36+2,1129 \mathrm{Rc} & \mathrm{R}^{2}=0,0015 \\
\mathrm{EI}_{30}=372,21 \mathrm{Rc}^{0,1591} & \mathrm{R}^{2}=0,0252
\end{array}
$$

As relações obtidas não foram significativas pois tanto a relação linear (Eq. 5) quanto a potencial (Eq. 6) apresentaram baixo coeficiente de determinação entre o índice $\mathrm{EI}_{30} \mathrm{e} o$ coeficiente de chuvas $(\mathrm{Rc})$ cujos resultados são semelhantes aos obtidos por vários pesquisadores, como foi o caso de Cassol et al. (2007) para Ijuí, RS, de Mazurana et al. (2009) para Santa Rosa, RS, e de Bertol (1994) para Campos Novos, SC; apesar disto observa-se, na Tabela 3, que o somatório dos valores mensais do $\mathrm{EI}_{30}$ estimados pela relação linear mostra uma aproximação muito boa com o valor médio anual (valor "R" da Equação Universal de Perdas de Solo); assim, infere-se que, para a região de São Gabriel, RS, pode-se utilizar dados de pluviometria para determinar o valor do fator "R" da Equação Universal de Perdas de Solo; entretanto, essas relações são inadequadas para a determinação da distribuição mensal do índice de erosividade das chuvas.

Outros pesquisadores, no entanto, obtiveram relações significativas entre o $\mathrm{EI}_{30}$ e o Rc, como Rufino et al. (1993), que apresentaram relação linear para oito regiões do Estado do Paraná, com coeficiente de correlação variando de $\mathrm{r}=0,84^{*}$
Tabela 3. Relações da erosividade com as quantidades de chuvas de São Gabriel, RS, no período de 1963

\begin{tabular}{|c|c|c|c|c|c|}
\hline \multirow{3}{*}{ Mês } & $\begin{array}{c}\text { Chuva média } \\
\text { mensal }\end{array}$ & $\begin{array}{l}\text { Coeficiente de } \\
\text { chuva - Rc }\end{array}$ & \multirow{2}{*}{$\begin{array}{c}\mathrm{El}_{30} \\
\text { observado }\end{array}$} & \multicolumn{2}{|c|}{$\mathrm{El}_{30}$ calculado } \\
\hline & \multirow{2}{*}{\multicolumn{2}{|c|}{ mm }} & & Eq. (5) & Eq. (6) \\
\hline & & & \multicolumn{3}{|c|}{ MJ mm ha-1 $h^{-1}$} \\
\hline Jan & 92,4 & 7,22 & 594,2 & 533,6 & 509,8 \\
\hline Fev & 97,0 & 7,95 & 711,5 & 535,2 & 517,7 \\
\hline Mar & 88,6 & 6,64 & 598,3 & 532,4 & 503,0 \\
\hline$A b r$ & 107,8 & 9,82 & 701,3 & 539,1 & 535,4 \\
\hline Mai & 108,9 & 10,03 & 567,7 & 539,5 & 537,1 \\
\hline Jun & 96,3 & 7,84 & 406,0 & 534,9 & 516,5 \\
\hline Jul & 122,2 & 12,62 & 416,1 & 545,0 & 557,2 \\
\hline Ago & 80,9 & 5,53 & 252,6 & 530,1 & 488,6 \\
\hline Set & 116,7 & 11,51 & 508,9 & 542,7 & 549,1 \\
\hline Out & 106,5 & 9,59 & 540,5 & 538,6 & 533,3 \\
\hline Nov & 87,3 & 6,44 & 539,9 & 532,0 & 500,6 \\
\hline Dez & 78,2 & 5,17 & 595,3 & 529,3 & 483,4 \\
\hline Total & $1.182,8$ & & $6.432,3$ & $6.432,4$ & $6.231,7$ \\
\hline
\end{tabular}
a 1993

a $r=0,93^{*}$, de Peñalva-Bazzano et al. (2007) que obtiveram correlação linear significativa $\left(\mathrm{EI}_{30}=-47,35+82,72 \mathrm{Rc}\right.$, $\left.\mathrm{R}^{2}=0,69 * * *\right)$ em Quaraí, RS, de Cassol et al. (2008) que encontraram correlação linear significativa para São Borja,

Tabela 4. Período de retorno e probabilidade de ocorrência dos valores dos índices anuais de erosividade,

\begin{tabular}{|c|c|c|c|c|}
\hline Ano & $\begin{array}{c}\text { Índice de } \\
\text { erosividade } \\
\left(\mathrm{El}_{30}\right) \\
\mathrm{MJ} \mathrm{mm} \mathrm{ha}^{-1} \mathrm{~h}^{-1}\end{array}$ & $\begin{array}{l}\text { Número } \\
\text { de ordem } \\
\text { (m) }\end{array}$ & $\begin{array}{l}\text { Período de } \\
\text { retorno } \\
\text { (T) } \\
\text { Ano }\end{array}$ & $\begin{array}{c}\text { Probabilidade de } \\
\text { ocorrência } \\
\text { (Pr) } \\
\%\end{array}$ \\
\hline 1987 & $12.096,5$ & 1 & 32,0 & 3,1 \\
\hline 1966 & $11.702,6$ & 2 & 16,0 & 6,3 \\
\hline 1986 & $10.981,1$ & 3 & 10,7 & 9,4 \\
\hline 1982 & $9.870,8$ & 4 & 8,0 & 12,5 \\
\hline 1972 & $9.854,8$ & 5 & 6,4 & 15,6 \\
\hline 1963 & $9.566,6$ & 6 & 5,3 & 18,8 \\
\hline 1984 & $7.870,6$ & 7 & 4,6 & 21,9 \\
\hline 1991 & $7.842,7$ & 8 & 4,0 & 25,0 \\
\hline 1976 & $7.776,1$ & 9 & 3,6 & 28,1 \\
\hline 1992 & $7.530,9$ & 10 & 3,2 & 31,3 \\
\hline 1988 & $6.789,2$ & 11 & 2,9 & 34,4 \\
\hline 1985 & $6.464,4$ & 12 & 2,7 & 37,5 \\
\hline 1973 & $6.336,0$ & 13 & 2,5 & 40,6 \\
\hline 1968 & $6.280,9$ & 14 & 2,3 & 43,8 \\
\hline 1970 & $6.206,2$ & 15 & 2,1 & 46,9 \\
\hline 1977 & $6.150,0$ & 16 & 2,0 & 50,0 \\
\hline 1979 & $6.146,3$ & 17 & 1,9 & 53,1 \\
\hline 1969 & $6.084,8$ & 18 & 1,8 & 56,3 \\
\hline 1983 & $5.912,8$ & 19 & 1,7 & 59,4 \\
\hline 1990 & $5.852,4$ & 20 & 1,6 & 62,5 \\
\hline 1975 & $5.685,4$ & 21 & 1,5 & 65,6 \\
\hline 1974 & $5.177,8$ & 22 & 1,5 & 68,8 \\
\hline 1993 & $4.846,0$ & 23 & 1,4 & 71,9 \\
\hline 1980 & $4.010,2$ & 24 & 1,3 & 75,0 \\
\hline 1965 & $3.793,7$ & 25 & 1,3 & 78,1 \\
\hline 1989 & $3.344,9$ & 26 & 1,2 & 81,3 \\
\hline 1964 & $3.277,4$ & 27 & 1,2 & 84,4 \\
\hline 1967 & $3.184,0$ & 28 & 1,1 & 87,5 \\
\hline 1978 & $3.133,9$ & 29 & 1,1 & 90,6 \\
\hline 1981 & $2.827,2$ & 30 & 1,1 & 93,8 \\
\hline 1971 & $2.808,9$ & 31 & 1,0 & 96,9 \\
\hline
\end{tabular}
de São Gabriel, RS, no período de 1963 a 1993 
$\mathrm{RS}\left(\mathrm{EI}_{30}=99,646+63,874 \mathrm{Rc}, \mathrm{R}^{2}=0,771\right)$ e de Almeida et al. (2011) ao obterem correlação potencial significativa ( $\mathrm{EI}_{30}$ $\left.=109,412 \mathrm{Rc}^{0,744}, \mathrm{R}^{2}=0,911^{* * * *}\right)$.

O período de retorno e a probabilidade de ocorrência de todos os eventos anuais de erosividade, no período 1963 a 1993, são mostrados na Tabela 4.

O maior valor de erosividade anual de 12.096,5 MJ mm $\mathrm{ha}^{-1} \mathrm{~h}^{-1}$ tem um período de retorno estimado de 32 anos, com probabilidade de ocorrência de $3,1 \%$. O menor valor de erosividade anual tem período de retorno de um ano e probabilidade de ocorrência de $96,9 \%$. Da mesma forma, o valor médio da erosividade anual (Fator R de 6.432,4 MJ $\mathrm{mm} \mathrm{ha}^{-1} \mathrm{~h}^{-1}$ para São Gabriel, RS) tem um período de retorno estimado de 2,65 anos, com probabilidade de ocorrência de $37,7 \%$ significando que há probabilidade de que a cada 2,65 anos ocorram chuvas anuais com potencial erosivo igual à média. Este valor do fator R encontrado para São Gabriel, RS, está dentro na faixa estabelecida para o Brasil, que é de 5.000 a $12.000 \mathrm{MJ} \mathrm{mm} \mathrm{ha}^{-1} \mathrm{~h}^{-1}$ ano $^{-1}$, de acordo com Cogo (1988) podendo o mesmo ser classificado como localidade de média erosividade, segundo classificação proposta por Foster et al. (1981).

\section{Conclusões}

1. O valor do fator "R" da Equação Universal de Perdas de Solos é de 6.432,4 MJ mm ha ${ }^{-1} \mathrm{~h}^{-1}$ que, para os valores do Rio Grande do Sul, pode ser considerado como de médio potencial erosivo.

2. O período de outubro a maio é o mais crítico em relação ao potencial erosivo das chuvas e o período de junho a setembro é o menos crítico.

3. O padrão hidrológico avançado é o de maior ocorrência tanto em número, volume e potencial erosivo das chuvas.

4. Supõe-se que o valor da erosividade média anual $\left(6432,4 \mathrm{MJ} \mathrm{mm} \mathrm{ha}^{-1} \mathrm{~h}^{-1}\right)$ ocorra uma vez a cada 2,65 anos, com probabilidade de ocorrência de $37,7 \%$.

\section{Literatura Citada}

Almeida, C. O. S; Amorim, R. S. S.; Couto, E. G.; Eltz, F. L. F.; Borges, L. E. C. Potencial erosivo da chuva de Cuiabá, MT: Distribuição e correlação com a precipitação pluviométrica. Revista Brasileira de Engenharia Agrícola e Ambiental, v.15, p.178-184, 2011.

Bertol, I. Avaliação da erosividade da chuva na localidade de Campos Novos (SC) no período de 1981-1990. Pesquisa Agropecuária Brasileira, v.29, p.1453-1458, 1994.

Carvalho, M.P.; Lombardi Neto, F.; Vasques Filho, J.; Cataneo, A. Índices de erosividade da chuva correlacionados com as perdas de um Podzólico Vermelho-amarelo textura argilosa/ muito argilosa de Mococa (SP): Primeira aproximação do fator erodibilidade dos solos. Revista Brasileira de Ciência do Solo, v.13, p.237-242, 1989.

Cassol, E. A.; Eltz, F. L. F.; Martins, D.; Lemos, A. M. de; Lima, V. S. de; Bueno, A. C. Erosividade, padrões hidrológicos, período de retorno e probabilidade de ocorrência das chuvas em São Borja, RS. Revista Brasileira de Ciência do Solo, v.32, p.1239-1251, 2008.
Cassol, E. A.; Martins, D.; Eltz, F. L. F.; Lima, V. S. de; Bueno, A. C. Erosividade e padrões hidrológicos das chuvas de Ijuí (RS), no período de 1963 a 1993. Revista Brasileira de Agrometeorologia, v.15, p.220-231, 2007.

CEMETRS - Centro Estadual de Meteorologia. Atlas climático do Rio Grande do Sul. Fundação Estadual de Pesquisa Agropecuária, Embrapa Clima Temperado e Embrapa Trigo. 2011. http://www.fepagro.rs.gov.br. 5 Mar. 2012.

Cogo, C. M.; Eltz, F. L. F.; Cassol, E. A. Erosividade das chuvas em Santa Maria, determinada pelo índice $\mathrm{EI}_{30}$. Revista Brasileira de Agrometeorologia, v.14, p.1-11, 2006.

Cogo, N. P. Conceitos e princípios envolvidos no manejo de solo para fins de controle da erosão hídrica. In: Congresso Brasileiro de Ciência do Solo, 21, 1988, Campinas. Anais... Campinas: SBCS, 1988. p.251-262.

Edwards, W. M.; Owens, L. B. Large storm effects on total soil erosion. Journal of Soil and Water Conservation, v.46, p.75-78, 1991.

Eltz, F. L. F.; Mehl, H. U.; Reichert, J. M. Perdas de solo e água em entressulcos em um Argissolo Vermelho-Amarelo submetido a quatro padrões de chuva. Revista Brasileira de Ciência do Solo, v.25, p.485-493, 2001.

Foster, G. R.; McCool, D. K.; Renard, K. G.; Moldenhauer, W. C. Conversion of the Universal Soil Loss Equation to SI units. Journal of Soil and Water Conservation, v.36, p.355-359, 1981.

Hickmann, C.; Eltz, F. L. F.; Cassol, E. A.; Cogo, C. M. Erosividade das chuvas em Uruguaiana, RS, determinada pelo índice $\mathrm{EI}_{30}$, com base no período de 1963 a 1991. Revista Brasileira de Ciência do Solo, v.32, p.825-831, 2008.

Horner, W. W.; Jens, S. W. Surface runoff determination from rainfall without using coefficients. Transactions of the ASCE, v.107, p.1039-1117, 1942.

Lombardi Neto, F. Rainfall erosivity - its distribution and relationship with soil loss at Campinas, Brazil. West Lafayette: Purdue University, 1977. 53p. Dissertação Mestrado

Mazurana, J; Cassol, E. A.; Santos, L. C. dos; Eltz, F. L. F.; Bueno, A. C. Erosividade, padrões hidrológicos e período de retorno das chuvas de Santa Rosa, RS. Revista Brasileira de Engenharia Agrícola e Ambiental, v.13, p.975-983, 2009.

Mehl, H. U.; Eltz, F. L. F.; Reichert, J. M.; Didoné, I. A. Caracterização dos padrões de chuva ocorrentes em Santa Maria (RS). Revista Brasileira de Ciência do Solo, v.25, p.475-483, 2001.

Morais, L. F. B de; Mutti, L. S. M.; Eltz, F. L. F. Índices de erosividade correlacionados com perdas de solo no Rio Grande do Sul. Revista Brasileira de Ciência do Solo, v.25, p.485-493, 1988.

Moreno, J. A. Clima do Rio Grande do Sul. Porto Alegre: Secretaria da Agricultura, 1961. 42p.

Peñalva-Bazzano, M. G.; Eltz, F. L. F.; Cassol, E. A. Erosividade, coeficiente de chuva, padrões e período de retorno das chuvas de Quaraí, RS. Revista Brasileira de Ciência do Solo, v.31, p.1205-1217, 2007.

Peñalva-Bazzano, M. G.; Eltz, F. L. F.; Cassol, E. A. Erosividade e características hidrológicas das chuvas de Rio Grande (RS). Revista Brasileira de Ciência do Solo, v.34, p.235244, 2010. 
Rufino, R.; Biscaia, R. C. M.; Merten, G. H. Avaliação do potencial erosivo da chuva do estado do Paraná, através de pluviometria: terceira aproximação. Revista Brasileira de Ciência do Solo, v.17, p.439-444, 1993.

Schwab, G. O.; Frevert, R. K.; Edminster, T. W.; Barnes, K. K. Soil and Water Conservation Engineering. 3.ed. New York: John Wiley \& Sons, 1981. 525p.
Wischmeier, W. H. A rainfall erosion index for a universal soilloss equation. Soil Science Society of America Proceedings, v.23, p.246-249, 1959.

Wischmeier, W. H.; Smith, D. D. Predicting rainfall erosion losses - a guide to conservation planning., Washington: USDA. 1978. 58p. Agriculture Handbook 537. 